\title{
The use of digital learning tools in the teachers' professional activities to ensure sustainable development and democratization of education in European countries
}

\author{
Oksana Ovcharuk*, Iryna Ivaniuk, Nataliia Soroko, Olena Gritsenchuk, and Oksana Kravchyna
}

Institute of Information Technologies and Learning Tools of NAES of Ukraine, Comparative Studies Department for Information and Education Innovations, Kyiv, 04060, Ukraine

\begin{abstract}
The article deals with the revealing and analysis of the experience of the teachers' use of the digital tools in their professional activities in the European countries (Germany, Italy, Netherland, Denmark, Estonia, Croatia, Sweden, Finland, Macedonia, Norway and others). The online recourses ensuring the creation of the sustainable environment for teachers and students including key competencies areas: entrepreneurship, citizenship, civic education and STEM are revealed in the article. The presented recourses allow to creative use of digital technologies, identify teachers' and students' needs and finding technological answers, solve technical problems, identifying gaps in digital competence. Using the analysed resources teachers become aware of the need to improve and update their digital competence; ability to support others in developing their digital competence; search for opportunities for self-development and awareness of digital evolution that is proclaimed by the UN '2030 Agenda for Sustainable Development' adopted in 2015. The objective is to present the examples of the use of digital tools by European teachers, which are aimed at building the digital environment, developing the digital competence, and introducing innovations in the learning process. The critical use of presented experience in the comparative perspective can improve domestic teaching practice and teachers' professional development.
\end{abstract}

\section{Introduction}

Ensuring the sustainable development of education in the framework of modern reforms is an important task of the Ukrainian state. This task is of particular importance in the context of the European integration processes taking place in education, as well as in the context of democratization of society, and revision of the methods and content of education. ICT as a tool can be used by teacher, who is acting in the multicultural environment in European countries. Teacher plays an important role in these processes. The modern teacher has to follow the best European teaching practices, to keep up with the innovations not only in his country but also in Europe.

Sustainable Development Goals (SDGs) are outlined in the document 'Transforming our world: the 2030 Agenda for Sustainable Development' adopted by the General Assembly of the United Nations stated in 2015 [1]. This resolution identified 17 Sustainable Development Goals including education. Goal 4 is to ensure inclusive and equitable quality education and promote lifelong learning opportunities for all.

The purpose of the article is to analyse the current trends in the use of digital learning tools in teachers' professional development and practice from the perspective of SDGs, democratization and reformation processes in Ukraine and Europe in the comparative perspective, and to reveal the approaches to the development of the sustainable, democratic, multicultural digital environment in the educational institutions. The research method involved analysing the current research and practices including the domestic and European experience of the use of digital tools in teachers' activities as well as learning courses for their professional development as a way of introducing innovative technology into their practice.

\section{Problem statements}

The SDGs (Goal 4) states that by 2030, substantially increase the number of youth and adults who have relevant skills, including technical and vocational skills, for employment, decent jobs and entrepreneurship. Also by 2030 , substantially expand globally the number of scholarships for enrolment in higher education, including vocational training and information and communications technology, technical, engineering and scientific programmes [1]. In the same time the development of information and communication competence (digital competence) of teachers is considered, today, as an integral part of the reform of education system as a whole. The main purpose is to have an educated specialist in accordance with the requirements of the democratic, multicultural and information society who has the necessary knowledge, skills and information

Corresponding author: oks.ovch@hotmail.com 
culture. The examples of the use of digital tools offered to the teachers in European countries are aimed at building the digital environment, developing the digital competence of the teacher and student, and introducing innovations in the learning process. Modern challenges of the European society require from educators to act in the multicultural digital environment, be prepared to propose their student's innovative ways of learning, communication, and investigation that will allow to form not only their digital skills but also prepare them to the labour market, entrepreneurship and citizenship.

The issues of development of digital literacy and competence as well as the use of and information and communication technologies in professional development are revealed in the number works, e.g. [2].

The article is aimed at the presentation of the different tools that teachers use across European countries under the common teaching aims. Comparative research of these tools lies in the fact that the authors try to show the diversity and common when using ICT for improving their digital learning strategies. Finally, the authors come to the proposals for the domestic in-service teacher training system on the improvement of the existing courses for teachers of different subjects regarding the development of their digital competence.

\section{Results and discussion}

According to the Conceptual Model of Digital Education presented by the Council of Europe considerable attention is given today to digital education, which is first and foremost about the opportunities not only to learn how to use digital resources, but also to have feedback on the use of ICT and the application of one's digital competence in work and study [3]. It is important that the learning tools are adaptable to the audience, and provide a feedback tool that better understands one's strengths and weaknesses, and that students and adults can find their own paths to success. Today the teacher should pay attention to the technological aspects of his/her digital competence, including:

- solving technical problems - the ability to identify technical problems in the operation of devices and use of digital environments, to be able to solve them (from troubleshooting to eliminating more significant difficulties);

- identifying needs and finding technological answers based on needs analysis the ability to identify, evaluate, select, use digital tools and possible technological answers to solve them. Ability to customize digital environments for personal needs (e.g., accessibility);

- creative use of digital technologies - the ability to use digital tools and technologies to create knowledge, innovative processes and products; engage individually and collectively in cognitive activities to understand and solve conceptual problems and solve problematic situations in digital environments;

- identifying gaps in digital competence - the ability to be aware of the need to improve or update one's digital competence; ability to support others in developing their digital competence; search for opportunities for self- development and awareness of modern digital evolution [3].

The digital skills, digital competence, digital citizenship is the subject of attention by a number of international organizations. Among them is the World Economic Forum, started in 1971, which is an international organization of public-private cooperation as a non-profit fund. The Forum attracts leading political, business and other leaders of society to form global, regional professional programs. In particular, the Forum supports the efforts of many public and private sector organizations, international organizations, and academic institutions in developing the economies of the countries that are implementing modern reforms. Starting in 2016, the World Economic Forum focuses on digital competence and relevant citizen skills and support for digital learning strategies. According to the Digital Economy and Society Index 2019 (DESI), all EU countries have improved their digital performance, with countries such as Finland, Sweden, the Netherlands and Denmark having the highest rankings in DESI 2019 and being one of the world leaders in digitalization and are today the most developed in the field of ICT use by their citizens. These countries are followed by the United Kingdom, Luxembourg, Ireland, Estonia and Belgium [4]. And although the level of ICT development in these countries allows citizens to use digital tools and develop their competence, it should be noted that according to the above report, $43 \%$ of Europeans do not yet have basic digital skills, even though $81 \%$ of Europeans turn to online resources at least 2 times for a week. It should also be noted that the largest number of Internet users are young people (97\% aged 16-24) and those with a high level of formal education (97\%). Thus, the use of digital technologies in life and work is an important indicator of the education, progress and level of use of ICT systems in education in Europe. Digital citizenship is closely linked to digital citizenship, a strategy that is actively pursued internationally. Digital citizenship, as a concept, is nowadays widely used by the European and global community to determine how citizens identify themselves, using ICT skills and competences.

In view of the above mentioned issues, the experience of using digital tools by teachers to carry out professional activities in the experience of European countries should be distinguished.

The documents of the Council of Europe, the European Union, the UNESCO, the UN recognize Multicultural Education as a fundamental principle that directs educational activities of educational institutions of different countries to the mutual recognition and interaction of cultures.

The Multicultural Education strategy emerged in response to the exacerbation of ethnic, national, and religious conflicts in modern society as a result of significant migration processes between countries in different regions of the world. Multicultural competence and multicultural dimension in education with ICT play a special role in lifelong learning today.

Consider, for example, two learning tools that teachers use in their work to shape the multicultural competence for themselves. The Multicultural 
Interdisciplinary Handbook was created as part of an international project during October 2009 - September 2011 with the financial support of the European Commission (Comenius program) [5]. The participating countries of the project were Austria, France, Germany, Italy, Poland, and Spain. The aim of the project was to create and distribute textbook, digital modules, a learning course for training future teachers of history and geography, and professional development of working teachers. The developed teaching materials help teachers to immerse themselves in the culture of other people through the study of geography and history, motivate them to study foreign languages. The handbook is presented online in six languages and can be used by all history and geography teachers interested in developing Multicultural Education. The digital modules are available free of charge in the form of video podcasts, content material (in HTML), standard training developments (in SCORM - IMS).

The multicultural experience of communicating with representatives of other countries and cultures is of great importance for the formation of multicultural competence. Therefore, one of the most effective means of forming multicultural competence is Culture Assimilator method [6].

The methods' goal is to teach a person to see different situations from the perspective of members of another's cultural group, to understand their vision of the world. The tasks of the cultural assimilator are the following: the acquisition of isomorphic attributions as the ways of interpretation of human behavior by representatives of foreign cultures; the experience of their emotional reactions in the circumstances of interethnic interactions and their correction; the formation of the tolerant behavior in a foreign cultural environment.

"Cultural Assimilators" is a training complex that includes: a brief description of situations where there is a problem of cultural adaptation or a problem related to cultural diversity between two interacting representatives of different cultures; four options for interpreting the behavior of the acting characters; explanations for each interpretation that involve discussing and determining the most appropriate answer.

Teachers can create and simulate problematic reallife situations for cultural assimilators using computer programs. Finnish scientist K. Korhonen has developed and implemented into the educational process of undergraduate students a "cultural assimilator" in the form of a web application called "The Same but Different" [7].

The analysis of educational scientific sources has made it possible to identify the following ICT tools that are widely used in the process of Multicultural Education: Web 2.0, virtual learning communities, educational electronic complexes, feature and educational films, thematic sites, online games, international educational online projects. Thus, ICT tools are today a new technological basis for the development of self-education skills, contribute to overcoming stereotypes, the formation of modern information culture and the required level of digital competence.
We can identify the main areas of use of digital learning tools by teachers in their professional activities, in particular for the formation of multicultural competence. Among them: distance courses in foreign languages and culture (OpenLearn platform: English, French, Gaelic, German, Italian, Welsh; Learn 48 Languages Online for Free: Spanish, Chinese, English \& More; Study.com (Spain), Livemocha gives access to free lessons for 35 languages and offers communication with the of native language speakers from 190 countries; e-learning programs for the development of multicultural understanding and awareness (Finland); multicultural and media education through ICT (Portugal, Romania, Poland, Latvia); creation of a multicultural educational environment in schools using ICT (Ireland, Netherlands, Denmark, Finland, Iceland, Belgium, Italy, Sweden, Latvia, Portugal); implementation of multicultural education through multimedia learning (Denmark, Estonia, Slovakia); use of the media to promote multicultural understanding and overcoming stereotypes (Germany, Estonia, United Kingdom); use of an electronic multicultural interdisciplinary handbook by teachers of history and geography (Austria, France, Germany, Italy, Poland, Spain); use of electronic educational resources in the process of multicultural education (Austria); the use of virtual simulation training games that reproduce multicultural aspects of life (Bulgaria, Estonia) and others.

One of the actual problems is the constant selfdevelopment, professional development and development of the digital competence of the teacher without leaving his job.

In this regard, Massive Open Online Courses (MOOCs) are being actively introduced in 2008; the idea was suggested by Dave Cormier from University of Prince Edward [8].

The topics for the courses are selected by experts and tutors according to the needs of society and globalization processes in Education.

For example, as part of the European Schoolnet Academy project is a free MOOCs that includes theoretical material in the form of texts and video lectures, webinars, videos of teachers of European countries with stories and lessons to share their professional experience, instructions for the practical use of ICT in the professional activity of participants of a course, their communication on social networks through course questions and professional solutions, tests for each module of the course and the end result, such as a lesson plan or other ICT training course. Participation in these courses and analysis of their tasks and topics during 2017-2019 years gave us the opportunity to highlight the following important problems regarding the modernization of the educational process and the professional development of the teacher according to inquiry-based pedagogy:

- to provide career information to motivate students and present a variety of STEAM and ICT-related jobs and skills required ("Teaching ICT with Inquiry"; "The Networked Teacher - Teaching in the 21st Century"; "Games in Schools"; "Personalised Learning in Practice - are my students driving their own learning?"; "Yes I 
can" - Empowering Student Learning"; “TeachUP Course: Collaborative Learning in Practice - are my students learning through collaboration?");

- to become familiar with innovative tools and approaches such as visual programming tools, unplugged activities, robotics, tinkering, and making and coding for all subjects ("EU Code Week - Deep Dive MOOC"; "The Networked Teacher - Teaching in the 21st Century"; "Games in Schools"; "Yes I can" Empowering Student Learning"; "TeachUP Course: Collaborative Learning in Practice - are my students learning through collaboration?"; "Boosting Bioeconomy Knowledge in Schools"; "Social Media Literacy for Change");

- to learn about active learning, innovative uses of ICT and collaborative teaching and learning ("Teaching ICT with Inquiry"; "EU Code Week - Deep Dive MOOC “; "The Networked Teacher - Teaching in the 21st Century"; "Games in Schools"; "Yes I can" Empowering Student Learning"; "TeachUP Course: Collaborative Learning in Practice - are my students learning through collaboration?"; "Boosting Bioeconomy Knowledge in Schools"; "Social Media Literacy for Change"; "Become the Next eSafety Champion").

In addition to suggestions on how to improve the effectiveness of teaching in the schools, these courses provide advice on the use of thematic portals and sites, training programs, computer games, and etc.

For example, "The Teaching ICT with Inquiry" course suggested using the Go-Lab ecosystem (https://www.golabz.eu/) to:

- students to conduct experiments in on-line laboratories in STEM fields, to participate in educational projects, in the implementation of which they need to use knowledge, skills and competences in the natural sciences, technologies, engineering, various fields of arts and mathematics;

- teachers to create and select didactic materials for teaching their subjects using the STEM approach, to share their pedagogical experience with colleagues from different countries of the world, etc.

Go-Lab ecosystem is projecting which creating since 2014. The Go-Lab initiative came about thanks to the successful Go-Lab project, which lasted from November 2012 to October 2016. The goal of the Go-Lab Initiative is to promote the use of online labs and applications for teaching and implementing research projects in schools. The Go-Lab Initiative provides a Go-Lab ecosystem for teachers where they can find various online labs and create their own learning spaces. The Go-Lab Initiative provides training for teachers across Europe on science education in schools and the use of the Go-Lab ecosystem. The Go-Lab initiative is currently funded by the Next-Lab project. The Go-Lab ecosystem consists of two main components. Go-Lab is a Sharing platform that provides hundreds of remote and virtual labs, as well as software or applications for query study. The Go-Lab platform enables teachers to create their own learning environments, combining labs, applications, and other resources for sharing with their students.
What is important about MOOCs is that the end result of each of these courses should be a personal training event developed by the course participant, such as a training project using the tools offered in the course. This result is evaluated using the peer-to-peer method.

It should be noted that the content of the courses is renewed every year, namely:

- new topics (e.g., the use of computer games to teach and teach different disciplines, training according to the needs of society, the use of new tools for monitoring, control and self-assessment of knowledge, skills and abilities of students and teachers);

- new tools for improve forms of learning (e.g., the use of new electronic platforms for STEAM projects in formal, non-formal, informal and inclusive learning; creation of computer-oriented environments, etc.);

- new lessons learned from teachers' experiences in implementing STEAM education in the schools (e.g., teaching STEAM projects, lessons on specific topics in STEAM fields, STEAM weeks, etc. using ICT); - updated country reports on the use of ICT in support of STEAM education and analysis of the results of implementation of the STEAM approach in the schools (e.g., Science education now: a renewed pedagogy for the future of Europe: https://ec.europa.eu/research/sciencesociety/document_library/pdf_06/report-rocard-onscience-education_en.pdf);

- new ideas are being generated to implement the STEAM approach in general education institutions (eg, to create websites that offer weeks of STEAM education in schools around the world: https://www.science-onstage.eu/page/display/5/28/13343/coding-in-stemeducation).

The experience of using digital technology teachers to gain knowledge in business education is interesting. This confirms the creation of European entrepreneurship education resources, such as the Virtual Entrepreneurship Education Handbook, which allows teachers from different countries to familiarize themselves with and use practical tools for primary, secondary and vocational education in their work.

Teachers from European countries are now successfully using the digital teaching HUB http://content.ee-hub.eu/. It brings together over 60 best practices in promoting entrepreneurship education in Europe on: national entrepreneurship education policy (Germany, Italy, Flanders, Denmark, Estonia, Croatia, Sweden, Finland, Macedonia, Norway, Denmark); teacher training (Enterprising School Program, Entrepreneurship360, Entrepreneurship Educators Program 3EP, 100 Mirrors, LIFE2 Project, STEP Model 2); partnerships (Cisco Networking Academy Networking, Combining Entrepreneurial Competence and STEM Industry Partnerships Skills, Accelerating the StartUp Ecosystem, YES - Finnish Regional Ecosystem Strategies to Implement National Strategies, Employee Volunteering - Added Value of Practical Entrepreneurial Programs, etc.); Entrepreneurship education ecosystem (integrates educational institutions of Spain, Serbia, Belgium, United Kingdom, Norway, Germany, Finland); tools (Measurement Tool for Enterprise Education 
(MTEE), Entre Intention Tool: Measuring Impact at the Individual Level Entre Intention Tool: Measuring Impact at Individual Level, EntreComp: Entrepreneurial Competence Framework, etc.); Financial Education (Interaction between Entrepreneurship and Financial Education, Financial Education Programs from Primary to Secondary Levels, MoneyIQ and MoneyOnline, Financial Education Curricula, Your Finances, Your Future; I Can Manage My Money) and others.

In order to effectively integrate entrepreneurship education into the school education process, modern digital tools are being used to help create resources and projects involving representatives from different countries. This digital resource is the Entrepreneurial School http://theentrepreneurialschool.eu/ [9], cofinanced by the European Commission, which includes 5 key objectives: teachers' continuing professional development and training; establishing quality supporting frameworks to measure best practice and to evaluate impact; development of appropriate support structures and activities; establishing networks between best practices; focusing on the initial education of teachers and the integration in the curriculum etc. The Entrepreneurial School project has trained over 4,000 teachers from 18 countries over the past three years, and has developed a Virtual Guide to Entrepreneurial Learning (http://www.tesguide.eu/default.aspx) [9, 10]. Focus groups from Denmark, Finland, Italy, Norway, Poland, Portugal, Slovakia and the United Kingdom worked on this development. The focus groups consisted of representatives of various education, business, government and citizenship institutions who were relevant to entrepreneurship education in their countries and played a key role in promoting entrepreneurship education.

Teachers in Europe are widely used by digital teaching platforms with open access by teachers to teaching resources. They are widely used in teacher training. For example, in the Netherlands, the following modern digital platforms should be distinguished: Teacher24 Learning Platform, created for educators from the Netherlands with the support of the Learning Cooperative and the National Educational Research Office (NRO) research organization, the Kennisnet Foundation, who work closely to support teachers' professional development in the use of ICT [Leraar24. URL: http://www.leraar24.nl (accessed: 12/24/2018)]. Launched in 2009, the Teacher24 platform (www.leraar24.nl) contains on-line teacher tools, including a variety of files and videos from a variety of teacher-created subjects [11].

On this platform, teachers can share their experiences with each other, offer their own techniques and discuss key issues, etc. Also, this resource hosts research in the field of pedagogy. In particular, this platform meets the new requirements of a competency-based approach supported by the professional teacher community. The central idea of the resource is the teacher's pedagogical, didactic and professional competence. The editorial board for scholarly publications teacher24.nl consists of teachers who make videos and write articles, edit and distribute these materials. For research-based articles, editors collaborate with researchers through the National Educational Research Administration (NRO) and the Kennisnet Foundation. By sharing knowledge and experience on teacher24.nl, teachers also communicate through social networks (Twitter or Facebook) that inspire each other to grow. LNE-Learning Network Education - an educational network for learning (http://www.leernetwerkeducatie.nl) supports online learning and acts as a communication platform between higher education institutions and practical training centers, through which the quality of hands-on learning is enhanced. Each student has the opportunity to create and develop their own profile in the learning environment. This allows increasing the quality control of practical training. The target group has a capacity of 15,000 users.

For the effective implementation of ICT in the national education system in the Netherlands, a Balance of Four model was developed (Netherlands, Vier In Balans). In order to have a positive pedagogical effect (benefits) of using ICT, it is necessary to ensure a balanced interaction of the four components: vision, experience, content and applications and content and infrastructure [11]. People as Educational Architects (Mensen Maken Scholen (https://www.paboinholland.nl)) is a simulation learning environment that offers educators the opportunity to create a virtual school and introduce themselves as a member of the school's team. the process in various roles, and "prevent" the students, creating problematic situations, and assist them in solving issues for further training to professional realities [12].

In general, public cloud services are widely depleted in Europe, offering many features designed specifically for a broad target audience. These are Google Apps for Education, Office 365 for Education, Dropbox, GSuite for Education, Apple Class kit / Classroom, and more. If publicly available cloud services lack the functionality required by the user or have problems with the terms of use, the institution may choose a private cloud.

\section{Conclusions}

The use of digital tools is recognized as appropriate by teachers of all subjects and school administrators. There is no doubt that modern pedagogical science requires a broader development of comparative pedagogical and empirical research in the field, highlighting important trends in the use of modern digital tools by teachers and providing guidance to decision makers. In this view it should be concluded that the use of digital tools and media by a teacher is closely linked to the digital competence, which requires the attention of the professional development system. A number of strategic documents have been developed by the international and European teaching community - a framework that relates to digital and civic competence as key competencies, an also the need to extensive use of digital tools in educational process. Ukraine has proclaimed a course on European integration of education, and educators today use educational guidelines and conceptual framework 
documents, including the Framework of the Competencies for Democratic Culture, the Digital Competence Framework for Teachers, and others. There is a lack of the in-service teacher training introducing civic education through ICTs, as well as in-service teacher training.

Further research should be done in the sphere of developing approaches and organizational and pedagogical conditions for teacher training in digital competence and digital citizenship, improving the methods and forms of using digital learning tools to create a democratic and sustainable environment in teachers' practice. In this respect, particular attention should be paid to the experience of those countries where the use of ICT at school and the development of teachers' digital competency are proclaimed as a strategic objective of education. Work on the implementation of these tasks should be carried out systematically, when teacher training is supported and encouraged by school leaders and the education system as a whole. The use of digital tools is recognized as appropriate by teachers of all subjects and organizers of extracurricular activities, which, in turn, diversify learning activities. There is no doubt that modern pedagogical science requires a broader deployment of comparative-pedagogical and empirical research in the field, highlighting important trends in the use of modern digital tools by teachers, and taking into account the need for sustainable development of education, as defined in the Sustainable Development Goals (2015).

\section{References}

1. Resolution adopted by the General Assembly on 25 September 2015. Transforming our world: the 2030 Agenda for Sustainable Development (2015), https://www.eea.europa.eu/policydocuments/resolution-adopted-by-the-general. Accessed 02 Feb 2020

2. Ye.O. Modlo, S.O. Semerikov, S.L. Bondarevskyi, S.T. Tolmachev, O.M. Markova, P.P. Nechypurenko, Methods of using mobile Internet devices in the formation of the general scientific component of bachelor in electromechanics competency in modeling of technical objects. CEUR Workshop Proceedings 2547, 217-240 (2020), http://ceur-ws.org/Vol-2546/paper16.pdf. Accessed 10 Feb 2020

3. Digital Education. A Conceptual Model (Council of Europe, 2019), https://www.coe.int/en/web/digitalcitizenship-education/a-conceptual-model. Accessed 02 Feb 2020

4. 8 digital life skills all children need - and a plan for teaching them (World Economic Forum, 2016), https://www.weforum.org/agenda/2016/09/8-digitallife-skills-all-children-need-and-a-plan-for-teachingthem/. Accessed 02 Feb 2020.

5. F.J. García Peñalvo, V. Zangrando, A.M. Seoane Pardo, A. García, Holgado, J. Szczecinska, J.M. Baldner, A. Consonni, C. Crivellari, Multicultural
Interdisciplinary Handbook. Tools for Learning History and Geography in a Multicultural Perspective (Comenius Multilateral Project. 502461-2009-LLP-ES-COMENIUS-CM, Salamanca (Spain), 2012)

6. The Centre for Learning and Teaching, Teaching International Students (University of Brighton, 2014),

https://staff.brighton.ac.uk/clt/published/Internationa 1-students-guidance\%20final.pdf. Accessed 14 Feb 2020

7. K. Korhonen, Intercultural Competence as Part of Professional Qualifications: A Training Experiment with Bachelor of Engineering Students (University of Jyväskylä, 2002), https://jyx.jyu.fi/dspace/bitstream/handle/123456789 $/ 13222 / 9513912930 . p d f$ ?sequence $=1$. Accessed 14 Feb 2020

8. K. Carey, Into the future with MOOCs (The Chronicle of Higher Education, 2012), https://www.chronicle.com/article/Into-the-FutureWith-MOOCs/134080. Accessed 14 Feb 2020

9. The Entrepreneurial School, Virtual Guide to Entrepreneurial Learning (2019), http://www.tesguide.eu/default.aspx. Accessed 12 Feb 2020

10. Digital Single Market. The Digital Economy and Society Index (DESI). (European Commission, 2019), https://ec.europa.eu/digital-singlemarket/desi. Accessed 08 Nov 2019

11. Four in Balance Monitor 2015. Use and benefits of ICT in education (Kennisnet, 2015), https://www.kennisnet.nl/fileadmin/kennisnet/corpor ate/algemeen/Four_in_balance_monitor_2015.pdf. Accessed 08 Feb 2019

12. Technology compass for education 2019 - 2020, (Kennisnet, 2019), https://www.kennisnet.nl/fileadmin/kennisnet/public atie/Kennisnet-Technology-Compass-20192020.pdf. Accessed 08 Feb 2019 